Original Articles

\title{
The cytoskeleton actin binding protein filamin A impairs both IGF2 mitogenic effects and the efficacy of IGF1R inhibitors in adrenocortical cancer cells
}

\author{
R. Catalano ${ }^{\text {a,b }}$, E. Giardino ${ }^{\text {a }}$, D. Treppiedi ${ }^{a}$, F. Mangili ${ }^{a}$, V. Morelli ${ }^{c}$, F.M. Elli ${ }^{c}$, A.L. Serban ${ }^{\text {b,c }}$,

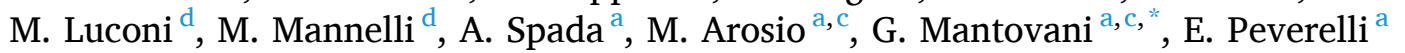 \\ ${ }^{\text {a }}$ Department of Clinical Sciences and Community Health, University of Milan, Milan, Italy \\ ${ }^{\mathrm{b}} \mathrm{PhD}$ Program in Endocrinological Sciences, Sapienza University of Rome, Rome, Italy \\ ' Endocrinology Unit, Fondazione IRCCS Ca' Granda Ospedale Maggiore Policlinico, Milan, Italy \\ ${ }^{\mathrm{d}}$ Department of Experimental and Clinical Biomedical Sciences, University of Florence, Florence, Italy
}

\section{A R T I C L E I N F O}

\section{Keywords:}

Adrenocortical carcinoma

Growth factors

Cytoskeleton

Linsitinib

NVP-ADW742

\begin{abstract}
A B S T R A C T
Adrenocortical carcinomas (ACCs) overexpress insulin-like growth factor 2 (IGF2), that drives a proliferative autocrine loop by binding to IGF1R and IR, but IGF1R/IR-targeted therapies failed in ACC patients.

The cytoskeleton actin-binding protein filamin A (FLNA) impairs IR signalling in melanoma cells.

Aims of this study were to test FLNA involvement in regulating IGF1R and IR responsiveness to both IGF2 and inhibitors in ACC.

In ACC cells H295R and SW13 and primary cultures (1ACC, 4 adenomas) we found that IGF1R and IR interacted with FLNA, and FLNA silencing increased IGF1R and reduced IR expression, with a downstream effect of increased cell proliferation and ERK phosphorylation.

In addition, FLNA knockdown potentiated antiproliferative effects of IGF1R/IR inhibitor Linsitinib and IGF1R inhibitor NVP-ADW742 in H295R.

Finally, Western blot showed lower FLNA expression in ACCs $(n=10)$ than in ACAs $(n=10)$ and an inverse correlation of FLNA/IGF1R ratio with ERK phosphorylation in ACCs only.

In conclusion, we demonstrated that low FLNA levels enhance both IGF2 proliferative effects and IGF1R/IR inhibitors efficacy in ACC cells, suggesting FLNA as a new factor influencing tumor clinical behavior and the response to the therapy with IGF1R/IR-targeted drugs.
\end{abstract}

\section{Introduction}

Adrenocortical carcinoma (ACC) is a rare endocrine tumor, developing from the adrenal cortex, with an incidence of 0.7-2 cases per million each year [1-3]. The prognosis is generally poor, with a 5-year overall survival of about $35 \%$ in most series and less than $20 \%$ in metastatic disease [4-6]. Complete surgical resection represents the only curative treatment for ACC, but recurrences are frequent. Inoperable or metastatic disease may benefit from systemic treatment with the adrenolytic agent mitotane, the only ACC-specific drug approved by the European Medicines Agency and the US Food and Drug Administration, but its efficacy is limited, highlighting the need for improved therapeutic strategies [3].
The pathogenesis of ACC is still poorly understood. In the last decades the involvement of different genes and pathways in the tumorigenesis and progression of ACCs has been highlighted. Among these emerged the role of $\beta$-catenin and Wnt signaling $[7,8]$. Moreover, one of the most frequent molecular change of ACC, observed in $80-90 \%$ of cases, is the overexpression of insulin-like growth factor 2 (IGF2), compared to normal adrenals and adrenocortical adenomas (ACAs) [9-17]. IGF2 promotes tumor growth in an autocrine loop by binding the receptor tyrosine kinase insulin-like growth factor 1 receptor (IGF1R) [18,19]. Moreover, IGF2 could interact with insulin receptor isoform A (IRA), expressed by ACC cells [20,21]. The binding of IGF2 to the receptors activates MAPK and PI3K/AKT/mTOR pathways, that culminate in increased cell proliferation, migration and protection from

\footnotetext{
* Corresponding author. Endocrinology and Diabetology Unit, Fondazione IRCCS Ca' Granda - Pad.Granelli, Via F. Sforza, 35, 20122, Milan, Italy.

E-mail address: giovanna.mantovani@unimi.it (G. Mantovani).
} 
apoptosis [22].

IGF2/IGF1R pathway overactivation in ACC was the rationale for studies testing the efficacy of pharmacological inhibitors of IGF1R, with promising results in preclinical in vitro and in vivo studies $[15,16]$. However, in a phase III trial a small molecule inhibitor of IGF1R and IR, Linsitinib (OSI-906), did not show an increased overall survival compared to placebo [23]. Anyway, few patients exhibited clinically relevant responses, including disease stabilization, tumor shrinkage, and long-term ACC regression [23], suggesting the urgent need for new biomarkers predicting the tumor responsiveness to this molecule, as well as for a better knowledge of the molecular mechanisms that govern IGF1R activity.

The cytoskeleton protein filamin A (FLNA) is crucial in the regulation of intracellular trafficking, expression and signal transduction of a number of membrane receptors and it plays a role in regulating clinical behavior of other endocrine [24,25] and non-endocrine tumors (reviewed in [26]). FLNA is a large actin binding protein able to homodimerize, composed of an N-terminal actin-binding domain and 24 Ig-like repeats of about 96 amino acids [27]. Interestingly, in melanoma cells FLNA directly bound to IR and impaired its ability to activate MAPKs [28]. The observation that loss of FLNA in mouse neural progenitor cells resulted in enhanced IGF1R signalling [29] likewise suggests a possible FLNA role in attenuating IGF1R signaling, but their interaction has yet to be proven.

In the present study we tested in ACC cell lines and primary cultured cells FLNA role in regulating IGF1R and IR expression and signaling, and in influencing the responsiveness to IGF1R/IR inhibitors. Moreover, we tested FLNA expression in human ACC tissues by Western blot analysis. Our results identify FLNA as a repressor of IGF2 signalling and recognize the loss of FLNA as a potential biomarker for ACC responsiveness to anti IGF1R/IR therapy.

\section{Materials and methods}

\subsection{Cell cultures and adrenal tissues}

Human adrenocortical carcinoma H295R cells (Cat\# CRL-2128, RRID: CVCL_0458, ATCC) and SW13 cells (Cat\# CCL-105, RRID: CVCL_0542, ATCC) were obtained from American Type Culture Collection. SW13 cells were tested and authenticated by genetic profiling using polymorphic short tandem repeat (STR) loci with PowerPlex Fusion system (Promega, BMR Genomics Cell Profile service, Italy) that allows to amplify 23 loci STR (D3S1358, D1S1656, D2S441, D10S1248, D13S317, Penta E, D16S539, D18S51, D2S1338, CSF1PO, Penta D, TH01, vWA, D21S11, D7S820, D5S818, TPOX, DYS391, D8S1179, D12S391, D19S433, FGA, D22S1045) and Amelogenin locus for gender determination. Results were compared to reference cell line databases (ATCC, DSMZ, JCRB and RIKEN) and the best matches were found. The analysis was carried out on May 17, 2018 and cells were subsequently used for less than 6 months for experiments. H295R cells were used for fewer than 6 months after receipt. For both cell lines the maximum passage number used for experimentation was 20. H295R cells were grown in DMEM:F12 1:1 (Cat\# 11320033, Gibco, Invitrogen, Life Technologies Inc, Carlsband, CA, USA) supplemented with 1\% ITS + Premix (Cat\# 355100, Corning, NY, USA), 2.5\% Nu-Serum I (Cat\# 354352, Corning, NY, USA), $2 \mathrm{mM}$ glutamine and $100 \mathrm{U} / \mathrm{ml}$ penicillin, and $100 \mu \mathrm{g} / \mathrm{ml}$ streptomycin (Cat\# 17-602E, Lonza group Ltd, Basel, Swi). SW13 cells were cultured in DMEM:F12 1:1, supplemented with $10 \%$ fetal bovine serum (FBS) (Cat\# 16000044, Gibco, Invitrogen, Life Technologies Inc, Carlsband, CA, USA), $2 \mathrm{mM}$ glutamine, $100 \mathrm{U} / \mathrm{ml}$ penicillin and $100 \mu \mathrm{g} / \mathrm{ml}$ streptomycin.

The human M2 melanoma cell line and the stable subclone, A7, were kindly gifted by Prof. Nakamura (Brigham and Women's Hospital, Boston, MA). Both cell lines were cultured in MEM (Cat\# M4655, Sigma Aldrich, St. Louis, MO) supplemented with 8\% Newborn Calf serum (Cat\# 16010159, Gibco, Invitrogen, Life Technologies Inc, Carlsband,
CA, USA), $2 \%$ FBS, $2 \mathrm{mM}$ glutamine, $100 \mathrm{U} / \mathrm{ml}$ penicillin and $100 \mu \mathrm{g} / \mathrm{ml}$ streptomycin. The A7 cells were grown with the addition of G418 disulfate salt $200 \mu \mathrm{g} / \mathrm{ml}$ (Cat\# A1720, Sigma Aldrich, St. Louis, MO) to maintain FLNA expression.

Fresh tissues (ACC, $n=1$, ACAs, $n=4$ ) were used to obtain primary cell cultures whereas frozen tissue samples (ACCs, $n=10$, ACAs, $n=10$ ) were subjected to protein extraction and subsequently analysed by Western blot. The study was approved by the local ethics committee and each patient gave informed consent to the use of his/her tumor sample and clinical information.

Briefly, fresh tissues were subjected to mechanical and enzymatic digestion using a solution of $2 \mathrm{mg} / \mathrm{mL}$ collagenase (Cat\# C9891, Sigma Aldrich, St. Louis, MO) dissolved in DMEM (Cat\# AL007A, Sigma Aldrich, St. Louis, MO) at $37{ }^{\circ} \mathrm{C}$ for $2 \mathrm{~h}$. In order to remove undigested material, the digested tissue was passed on a 100- $\mu \mathrm{m}$ filter (nylon cell strainer, BD Transduction Laboratories, Lexington, UK) and the obtained cell suspension was centrifuged (1000 rpm, $10 \mathrm{~min}$ ). After this centrifugation step, cells were pelleted at the bottom of the tube, while adipocytes were found on the surface as a ring due to their low density. At this step, the adipocyte ring was transferred to a new tube and discarded. Pelleted cells were cultured in DMEM supplemented with $20 \%$ FBS, 2 $\mathrm{mM}$ glutamine and $100 \mathrm{U} / \mathrm{ml}$ penicillin, and $100 \mu \mathrm{g} / \mathrm{ml}$ streptomycin.

Frozen tissues were subjected to mechanical dissection with the use of a scalpel, lysed in $100 \mu \mathrm{l}$ of lysis buffer (Cat\# 9803S, Cell signalling technology, Danvers, MA), with the addition of protease inhibitors (Roche, Monza, IT) for $10 \mathrm{~min}$ on ice, then centrifuged at $1200 \mathrm{rpm}, 10$ min at $4{ }^{\circ} \mathrm{C}$. The supernatant containing extracted proteins was collected in fresh tube. Proteins were quantified by BCA assay.

\subsection{Coimmunoprecipitation assay}

Immunoprecipitation was performed as previously described [30]. To avoid interference of growth factors present in cell culture media, the experiments were performed in the absence of serum, and supplemental factors (ITS + premix), thus in DMEM:F12 1:1. Cells were then stimulated or not with IGF2 $100 \mathrm{ng} / \mathrm{ml}$ (Cat\# 100-12, Peprotech, Rocky Hill, $\mathrm{NJ}, \mathrm{USA})$. Briefly, $100 \mu \mathrm{g}$ of total protein extracted from cells were incubated on a rotating device with $4 \mu \mathrm{g}$ FLNA antibody (Cat\# H00002316-M01, RRID:AB_425437; Abnova Corporation, Tapei City, Taiwan) for $16 \mathrm{~h}$ at $4{ }^{\circ} \mathrm{C}$ and then with $20 \mu \mathrm{l}$ of protein A/G Plus-Agarose for $3 \mathrm{~h}$ at $4{ }^{\circ} \mathrm{C}$ (Cat\# sc-2002, Santa Cruz Pharmaceutical Inc, Santa Cruz, CA). Mouse IgG1 isotype control (Cat\# MA1-10404, RRID: AB_2536772; Thermo Fisher Scientific, Rockford, IL) was used as negative control to measure the non-specific binding. Eluted proteins were resolved by SDS-PAGE and transferred to a nitrocellulose filter. Immunoblotting was performed with anti-FLNA antibody $(1: 1000$ dilution), anti-IGF1R (Cat\# 28897, RRID:AB_2798965, Cell Signaling Technology, Danvers, MA; 1:1000 dilution) and anti-IR antibodies (Cat\# 3025, RRID:AB_2280448, Cell Signaling Technology, Danvers, MA; $1: 1000$ dilution).

For IGF1R and IR immunoprecipitation, $400 \mu \mathrm{g}$ of total protein extracted from cells were incubated on a rotating device with IGF1R antibody (dilution 1:100) or IR antibody (dilution 1:50).

\subsection{In situ proximity ligation assay (PLA)}

PLA experiments were performed using reagents and instructions provided by a commercially available kit (Duolink In Situ Detection Reagents Red) from Sigma-Aldrich (St Louis, MI, USA). H295R were plated at the density of $1.5 \times 10^{5}$ cells/well and SW13 at $2 \times 10^{4}$ cells/ well on 13-mm poly-L-lysine (Cat\# P4707, Sigma-Aldrich, St Louis, MI, USA) coated coverslips in 24-well plates. Both were cultured in a starved culture medium and free of ITS + Premix for H295R, and stimulated or not with IGF2 $100 \mathrm{ng} / \mathrm{ml}$.

Cells were fixed for $10 \mathrm{~min}$ at room temperature with $4 \%$ paraformaldehyde (Cat\# P6148, Sigma-Aldrich, St. Louis, MO), followed by 
three washes with PBS and incubated $1 \mathrm{~h}$ at room temperature with blocking buffer (5\% FBS, 0.3\% Triton ${ }^{\mathrm{TMX}}-100$, in PBS). The overnight incubation with anti-FLNA $(1: 200)$ and anti-IGF1R (1:100) or anti-IR (1:50) antibodies was performed at $4{ }^{\circ} \mathrm{C}$. The following day, secondary probes anti-mouse and anti-rabbit attached to oligonucleotides were added and, after washing, the oligonucleotides of the bound probes where ligated and then amplified. Finally, slides were mounted with Duolink Mounting Medium with 4',6 diamidino-2-phenylindole (DAPI) on glass slides and analysed by fluorescence microscopy (Axio Vert.A1, Zeiss). PLA probe incubation time and rolling circle amplification times were all optimized for this specific application. Technical negative control slides were prepared with omission of each primary antibody separately and omission of all primary antibodies. Proximity ligation events were quantified with NIH ImageJ software after image deconvolution in agreement with previously published approaches [31].

\subsection{FLNA and IGF1R silencing}

Small interfering RNAs (siRNAs) against human FLNA and IGF1R gene were purchased from Dharmacon (Cat\# FE5L003012000005, Smart pool siRNAs, Dharmacon, GE Healthcare Life Sciences, Chicago, IL, USA). Subconfluent H295R cells were transfected with FLNA siRNAs using Viromer Blue for miRNA/siRNA transfection reagent (Cat\# VB01LB-01, Lipocalyx GmbH, Halle, D) and SW13 cells with Dharmafect transfection agent 2 (Cat\# T-2002-03, Dharmacon, GE Healthcare Life Sciences, Chicago, IL), according to manufacturer's instructions. Preliminary experiments aimed to determine the optimal concentration of siRNAs and the kinetics of silencing of FLNA and IGF1R alone and together were performed. In each experiment a negative control siRNA, a non-targeting sequence without significant homology to the sequence of human, mouse or rat transcripts was used. Western blotting was performed in each experiment to control the expression level of FLNA, IGF1R and FLNA + IGF1R in silenced cells with 1:1000 dilution of antiFLNA antibody and anti-IGF1R. The membranes were stripped and reprobed with an anti-GAPDH antibody (Cat\# AM4300, RRID: AB_437392; Ambion, Life Technologies Inc, Carlsband, CA, 1:4000 dilution). Only experiments with silencing efficiency $>80 \%$ were accepted. Experiments were repeated at least 3 times.

\subsection{FLNA transfection}

Transient transfections of the plasmid encoding FLNA (pREP 4 filamin A expression vector) [30] were performed using Lipofectamine 2000 transfection reagent (Invitrogen) according to the manufacturer's instruction. An empty vector was used in each experiment as negative control. Western blot analysis was performed in each experiment to control the expression level of FLNA in transiently transfected cells. Experiments were repeated at least 3 times.

\subsection{Western blot analysis}

Total proteins extracted from cultured cells were quantified by BCA assay, separated on SDS/polyacrylamide gels and transferred to a nitrocellulose filter. Anti-IGF1R, anti-IR, anti-Cyclin E1 (Cat\# 4129, Cell Signaling Technology, Danvers, MA), anti-Caspase-3 (Cat\# 9662, Cell Signaling Technology, Danvers, MA), phospho and total p44/p42 MAPK ERK1/2 (Cat\# MAB-91982 and Cat\# AB-82379, respectively, Immunological Sciences, Rome, Italy), total AKT (Cat\# MAB-94324, Immunological Sciences, Rome, Italy), were used at 1:1000. Phospho-AKT (Ser473) antibody was used at 1:2000 (Cat\# ABP-0637, Immunological Sciences, Rome, Italy) and IGF2 antibody (Cat\# ab9574, Abcam, Cambridge, UK) was used $0.2 \mu \mathrm{g} / \mathrm{ml}$. The detection of phosphorylated proteins was normalized on total proteins. GAPDH was used as housekeeping. Chemiluminescence was detected using the Chemidoc-IT Imaging System (UVP, Upland, CA) and densitometrical analysis was performed with NIH ImageJ software. Experiments were repeated at least 3 times.

\subsection{Cell proliferation assay}

Cell proliferation was assessed by colorimetric measurement of 5bromo-2-deoxyuridine (BrdU) incorporation during DNA synthesis in proliferating cells as previously reported [32], according to the instruction of the manufacture (GE Healthcare, Life Science, Buckinghamshire, UK). Cells were plated in a 6-well plate at the density of 3 $\times 10^{5}$ for H295R, $1 \times 10^{5}$ for SW13 and $2.5 \times 10^{5}$ for ACA primary cultured cells $(n=4)$ and after FLNA silencing of $72 \mathrm{~h}$ were transferred in a p96 multiwell at a density of $1.7 \times 10^{4}$. After that, cells were treated or not with: Linsitinib (Cat\# S1091, Selleck Chemicals, Houston, TX, USA) or NVP-ADW742 (Cat\# SML1921, Sigma Aldrich, St. Louis, MO) at indicated concentration or only with IGF2 $100 \mathrm{ng} / \mathrm{ml}$ for $24 \mathrm{~h}$. SW13 cells after incubation with IGF1R or IGF1R/IR inhibitor were also treated with IGF2 $100 \mathrm{ng} / \mathrm{ml}$ for additional $24 \mathrm{~h}$. BrdU was added to $\mathrm{H} 295 \mathrm{R}$ and SW13 for $2 \mathrm{~h}$ and to ACAs for $24 \mathrm{~h}$ at $37^{\circ} \mathrm{C}$. All experiments were repeated at least 3 times and each determination was done in triplicate.

\subsection{Apoptosis assay}

Caspase-3/7 enzymatic activity was measured using Apo-ONE Homogeneous Caspase-3/7 Assay (Promega, WI, USA) according to the instruction of the manufacturer. Silenced cells were seeded at a density of $1.7 \times 10^{4}$ cells/well in a 96-well plate. The amount of fluorescent product generated from a profluorescent caspase- $3 / 7$ consensus substrate is representative of the amount of active caspase- $3 / 7$ present in the sample. Experiments were repeated 3 times and each determination was done in quintuple.

\subsection{Statistical analysis}

The results are expressed at the mean \pm S.D. A paired two-tailed Student's t-test was used to assess the significance between two series of data. ACAs vs ACCs densitometric data were analysed by the nonparametric Pearson chi-squared test. Spearman's correlation coefficient was used to show direct correlations. Calculations were performed by GraphPad Prism 7.0 software (GraphPad Software, Inc, La Jolla, CA). $\mathrm{p}<0.05$ was accepted as statistically significant.

\section{Results}

\subsection{In ACC cell lines FLNA interacts with IGF1R and IR}

We used two human cell lines, the ACC cell line H295R, and SW13 cells, a model useful to test the absence of IGF2, although of uncertain adrenocortical derivation. According to published data [16,33-35], we found that only H295R express IGF2 protein (data not shown), and that both cell lines express IGF1R, IR and FLNA at comparable levels (Suppl. Fig. 1A-C).

It has been shown that FLNA interacts directly with IR in glutathione S-transferase (GST) pull-down assays and immunoprecipitation assays in A7 melanoma cells [28], while no data are available demonstrating FLNA-IGF1R interaction.

Here, we used two different techniques to analyze the interaction between IGF1R-FLNA and IR-FLNA both in the presence and absence of IGF2.

Immunoprecipitation assays of FLNA in H295R cells showed that FLNA was able to coimmunoprecipitate IGF1R in basal conditions (Fig. 1A). Moreover, $10 \mathrm{~min}$ stimulation with IGF2 $100 \mathrm{ng} / \mathrm{ml}$ increased the recruitment of FLNA to the receptor $(1.7 \pm 0.1$-fold $v s$ basal, $\mathrm{p}<$ 0.001 ), that remains stable at $30 \mathrm{~min}$ of incubation with IGF2. Since H295R cells, but not SW13 cells, express and secrete in culture medium large amounts of IGF2 $[16,34,35]$, to test the interaction IGF1R-FLNA in 

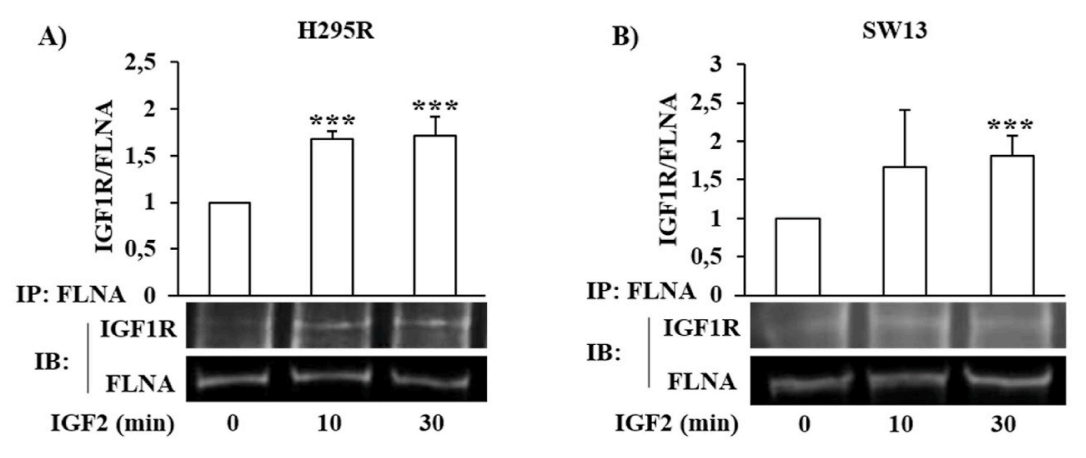

C)

H295R

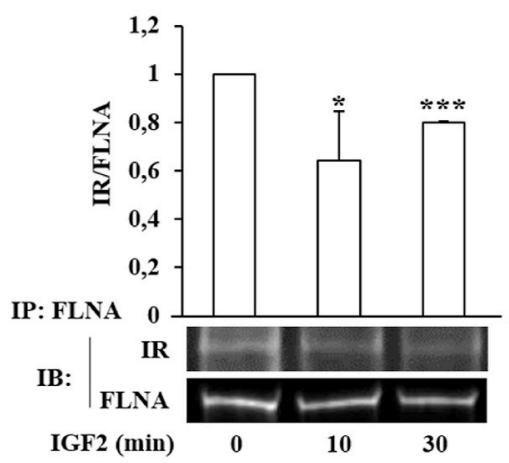

D)

SW13

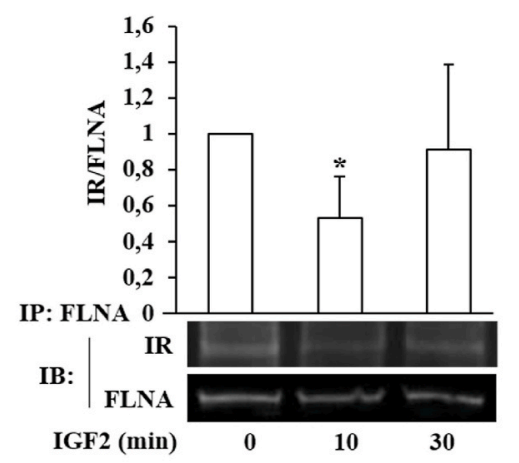

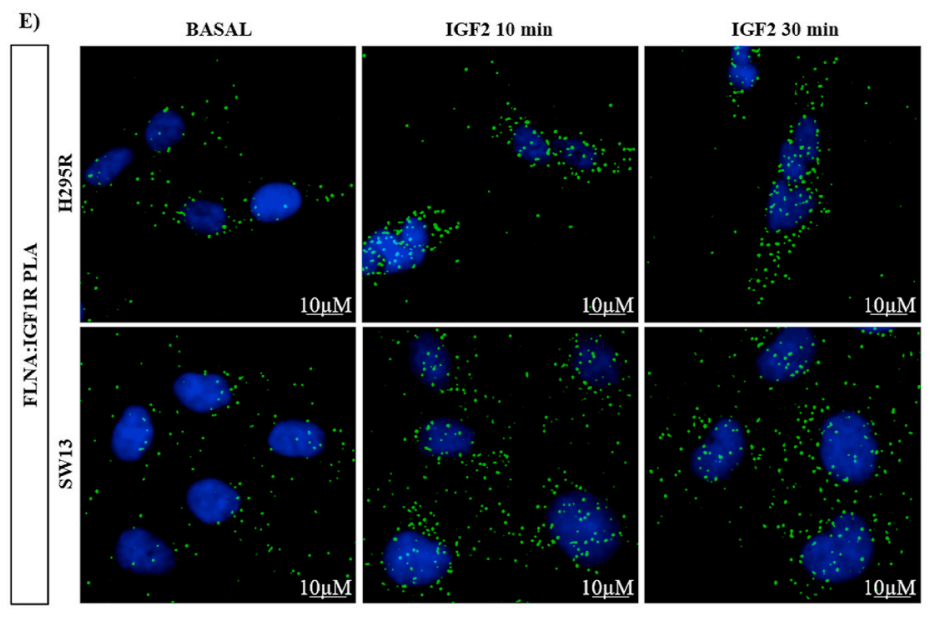
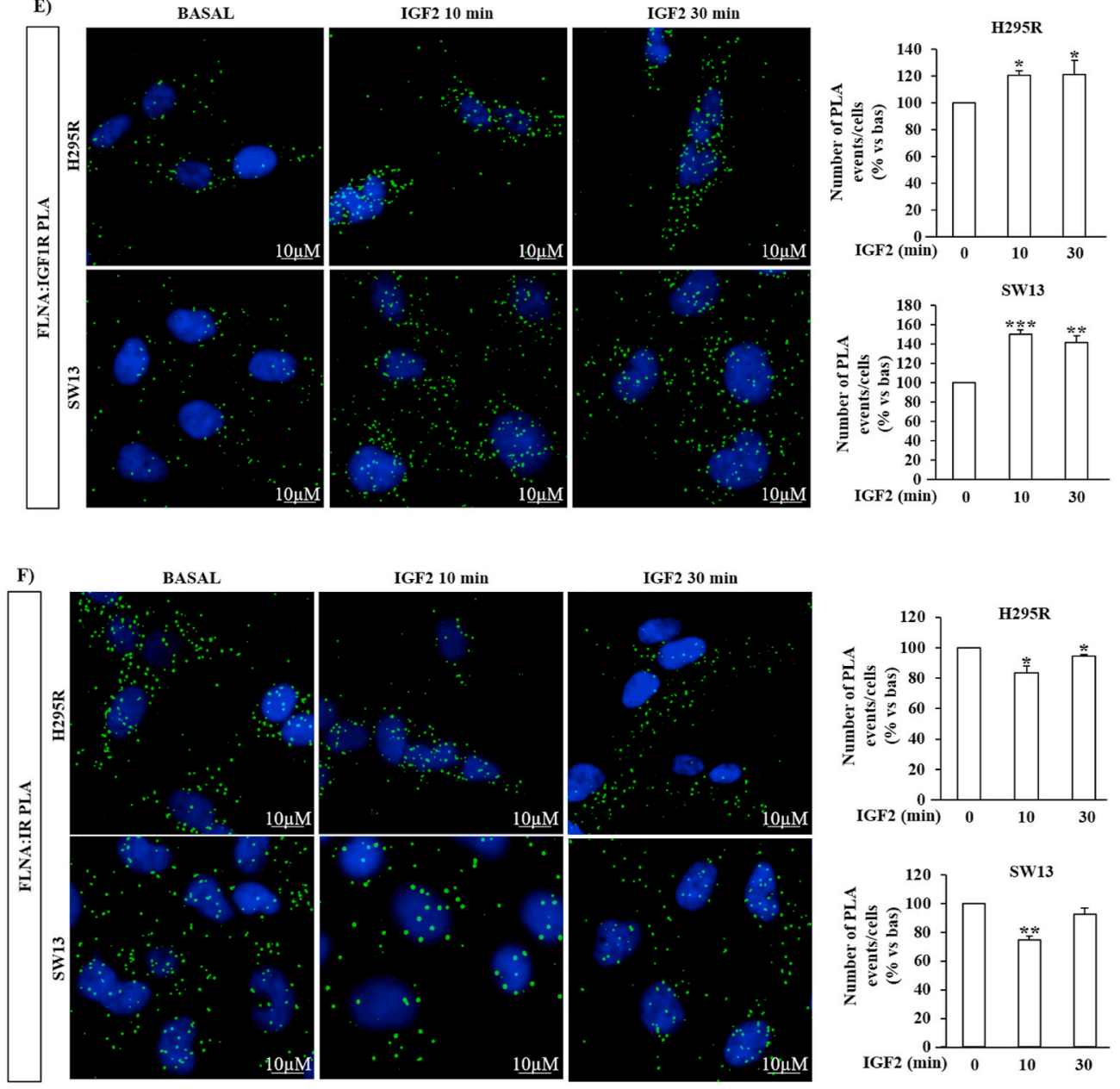
Fig. 1. Interaction of FLNA with IGF1R and IR. A-D) Coimmunoprecipitation assays. H295R and SW13 were treated for the indicated times with $100 \mathrm{ng} / \mathrm{ml}$ IGF2. Lysates were immunoprecipitated with FLNA antibody and the presence of IGF1R, IR and FLNA in immunoprecipitates was tested by immunoblotting. Representative images of one of 3 independent experiments are shown. The graphs show mean \pm S.D. from 3 independent experiments, normalized $v s$ basal. $*=\mathrm{p}<0.05, * * *=\mathrm{p}<0.001 v s$ basal. E\&F) FLNA-IGF1R and FLNA-IR interaction tested by proximity ligation assay (PLA) in H295R and SW13 cells. Cells were incubated or not with $100 \mathrm{ng} / \mathrm{ml} \mathrm{IGF2.}$ Each picture represents a typical cell staining observed in 10 fields randomly chosen. Positive PLA signals are visualized as green fluorescent spots. Nuclei are stained with DAPI (blue). Scale bar $10 \mu \mathrm{m}$. Quantification of total FLNA-IGF1R (E) and FLNA-IR (F) puncta representing PLA events are shown ( $n=3$ and $\sim 2000$ total puncta quantified per condition in cells randomly chosen from different fields, $*=\mathrm{p}<0.05,{ }^{* *}=\mathrm{P}<0.01$, $* * *=\mathrm{p}<0.001)$.

the absence of IGF2 we used SW13 cells. Our results showed the presence of IGF1R in the immunoprecipitates also in basal condition (Fig. 1B), suggesting a constitutive interaction between IGF1R and FLNA. As observed in H295R, FLNA recruitment to IGF1R increased after IGF2 stimulation ( $1.8 \pm 0.3$-fold at $30 \mathrm{~min} v s$ basal, $\mathrm{p}<0.001)$.

In both ACC cell lines, FLNA was able to coimmunoprecipitate IR in basal conditions. IR interaction with FLNA was transient and decreased after stimulation with IGF2 $(-35.7 \pm 20.2 \%$ and $-46.7 \pm 22.6 \%$ after 10 min IGF2 incubation in H295R and SW13, respectively, p < 0.05) (Fig. 1C\&D).

The interaction of FLNA with IGF1R and IR in H295R and SW13 cells was confirmed by immunoprecipitating the receptors and blotting for FLNA (Suppl. Fig.2).

We then performed in situ proximity ligation assay (PLA) between FLNA and IGF1R or IR in H295R and SW13 cells. Consistently, the presence of PLA signals (green dots) indicate a close proximity (at distances $<40 \mathrm{~nm}$ ) between IGF1R and FLNA (Fig. 1E) and IR and FLNA (Fig. 1F) in both cell lines. Furthermore, the quantification analysis of PLA signals confirmed a significantly enhancement of IGF1R-FLNA interaction $(120.7 \pm 3.4 \%, \mathrm{p}<0.05$ and $149.6 \pm 4.78 \%, \mathrm{p}<0.001$ in H295R and SW13, respectively, Fig. 1E) and a reduction of IR-FLNA $(-16.6 \pm 4.4 \%, \mathrm{p}<0.05$ and $-25.6 \pm 2.85 \%, \mathrm{p}<0.01$ in H295R and SW13, respectively, Fig. 1F) after $10 \mathrm{~min}$ of incubation with IGF2.

\subsection{FLNA silencing increases IGF1R and decreases IR expression}

To test the effects of FLNA on IGF1R and IR expression, we silenced cells with siRNAs specific for FLNA.

In H295R cells, IGF1R expression levels were significantly increased in FLNA silenced cells with respect to cells transfected with negative control siRNAs $(1.4 \pm 0.2$-fold, $\mathrm{p}<0.01)$. In SW13 cells, that do not secrete IGF2, in contrast to H295R, FLNA knockdown did not alter IGF1R in basal condition, but strongly increased IGF1R expression upon 24 h IGF2 incubation $(2.3 \pm 0.8$-fold $v s$ IGF2 stimulated control cells, $\mathrm{p}$ $<0.05)$ (Fig. 2A\&B).

In contrast, FLNA silencing reduced IR expression, both in H295R cells $(-85.5 \pm 9.1 \%, \mathrm{p}<0.001)$ and in SW13 cells after IGF2 stimulation $(-27.2 \pm 18.2 \%$ vs IGF2 stimulated control cells, $\mathrm{p}<0.05)$ (Fig. 2C\&D).

To replicate these experiments in ACC primary cultured cells, we tested 3 ACCs for FLNA expression. Only one expressed FLNA at detectable levels, and was used for FLNA silencing experiments. In primary cultured ACC cells, FLNA silencing increased IGF1R expression (2.9-fold $v s$ control cells) but did not alter IR expression levels (Fig. 2E).

To test a possible effect of FLNA overexpression on the amount of IGF1R and IR, we transiently transfected FLNA in H295R cells. We found that FLNA overexpression did not impact on IGF1R and IR expression (Fig. 2F\&G).

\subsection{FLNA silencing increases IGF2 proliferative effects}

We then examined the effects of FLNA silencing on the intracellular responses elicited by IGF2. H295R cells proliferation was significantly increased $(130 \pm 13.4 \%, \mathrm{p}<0.01)$ in FLNA silenced cells compared to negative control cells (Fig. 3A). In SW13 cells, FLNA knockdown increased basal cell proliferation $(131.2 \pm 6.7 \%$ vs control cells, $\mathrm{p}<$ $0.001)$ and enhanced the mitogenic effects of IGF2 (144.3 $\pm 23.8 \% v s$ IGF2 stimulated control cells, $\mathrm{p}<0.05$ ) (Fig. 3B).

In agreement, by measuring ERK phosphorylation, we found that FLNA silencing in H295R cells induced an increase of P-ERK/total ERK ratio $(1.3 \pm 0.1$-fold $v s$ control cells, $\mathrm{p}<0.01)$, that was completely abolished in the absence of IGF1R in double-silenced cells, suggesting that ERK phosphorylation is increased by FLNA silencing downstream IGF1R signalling (Fig. 3C).

Accordingly, we found a significant increase in cyclin E1 expression after FLNA silencing in H295R ( $1.55 \pm 0.3$-fold $v s$ control cells, $\mathrm{p}<0.05$ ) (Fig. 3D).

On the contrary, cell apoptosis was not affected by FLNA silencing, as demonstrated by caspase 3/7 activity assay (Fig. 3E) and by the Western blot analysis of pro-caspase 3 and cleaved caspase 3 (Fig. 3F), in H295R cells. In line with these results, we found that FLNA silencing in H295R cells did not change P-AKT/total AKT ratio (Fig. 3G).

In primary ACC cells, FLNA silencing strongly increased ERK phosphorylation (4.3-fold vs control cells) (Fig. 3H). IGF2 as expected promoted ERK phosphorylation in control cells (2.2-fold increase), but only slightly further increased ERK phosphorylation in FLNA silenced cells with respect to basal (1.14-fold). However, it should be noted that pERK/ERK ratio upon IGF2 incubation was 2.2-fold higher in FLNA silenced cells vs control cells (Fig. $3 \mathrm{H}$ ). 
A)

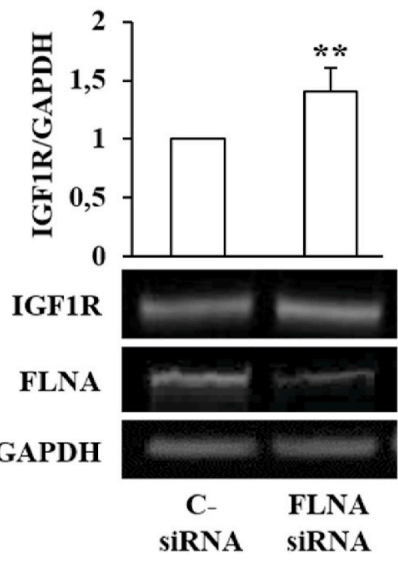

B)

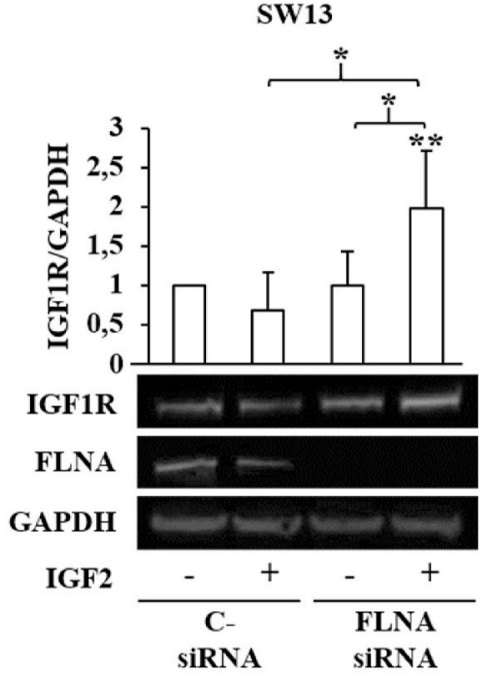

C)
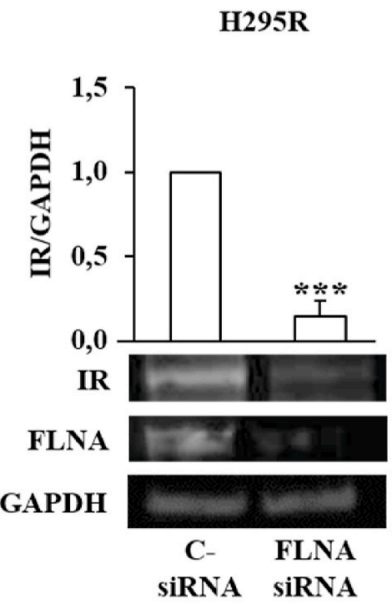

F)

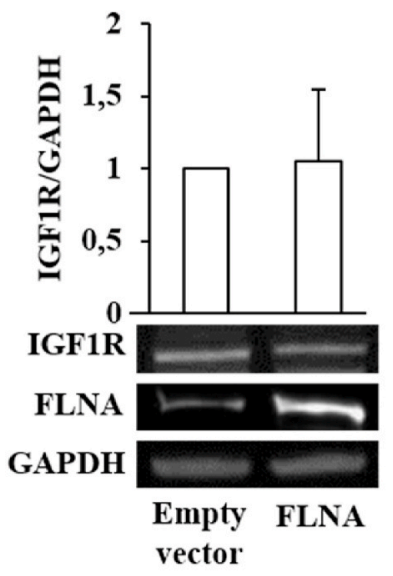

D)

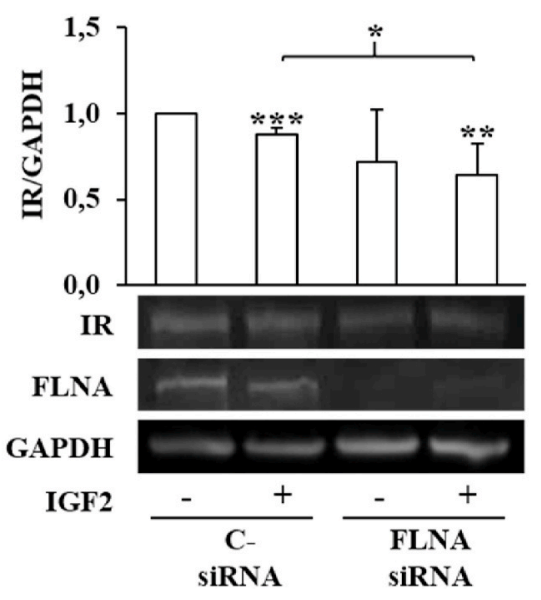

E) ACC primary cultured cells
G)

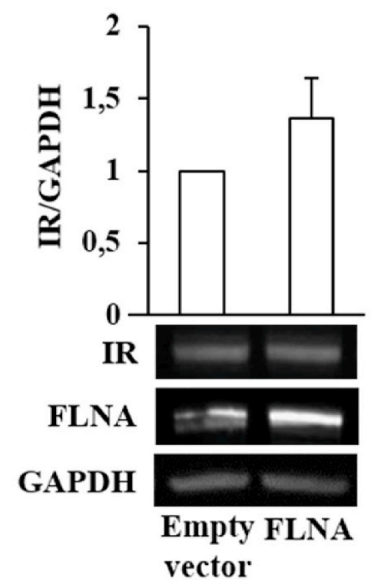

Fig. 2. FLNA silencing increases IGF1R and decreases IR expression. H295R (A\&C), SW13 (B\&D) and ACC primary cultured cells (E) were transiently transfected with FLNA siRNAs or negative control siRNAs (C- siRNA) for $72 \mathrm{~h}$. SW13 cells were also treated or not with IGF2 $100 \mathrm{ng} / \mathrm{ml}$ for $24 \mathrm{~h}$. Membranes were incubated with FLNA, IGF1R or IR antibodies, stripped and reprobed with anti-GAPDH antibody. The graphs show densitometrical analysis of IGF1R (A\&B) or IR (C\&D) normalized to GAPDH (mean \pm S.D. from 3 independent experiments). Representative immunoblots are shown. ${ }^{*}=\mathrm{p}<0.05,{ }^{* *}=\mathrm{p}<0.01,{ }^{* * *}=\mathrm{p}<0.001$. E) IGF1R and IR expression in ACC primary cultured cells silenced for FLNA. FLNA silencing induced an increase of IGF1R expression compared to control cells. F\&G) IGF1R and IR expression in H295R transiently transfected with wild type FLNA expression vector for $48 \mathrm{~h}$. Membranes were incubated with FLNA, IGF1R or IR antibodies, stripped and reprobed with anti-GAPDH antibody. The graphs show densitometrical analysis of IGF1R (F) or IR (G) normalized to GAPDH (mean \pm S.D. from 3 independent experiments). Representative immunoblots are shown. 
A)

H295R

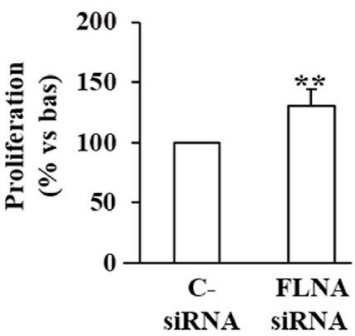

C)

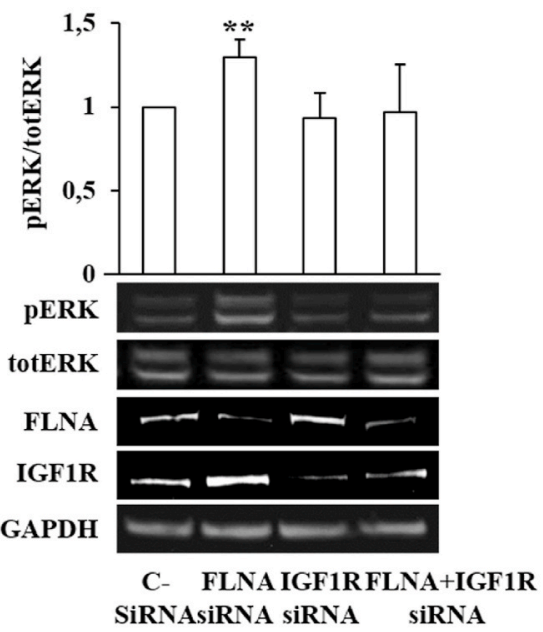

B)

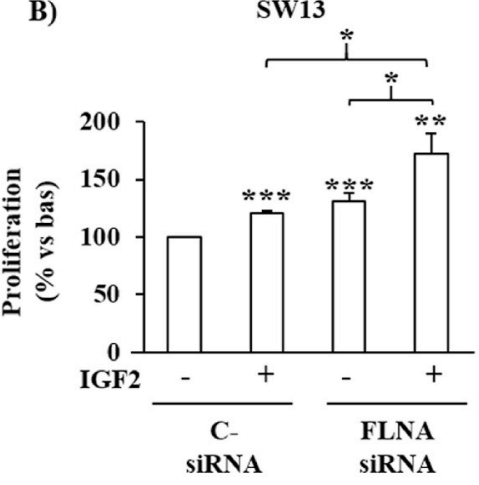

D)

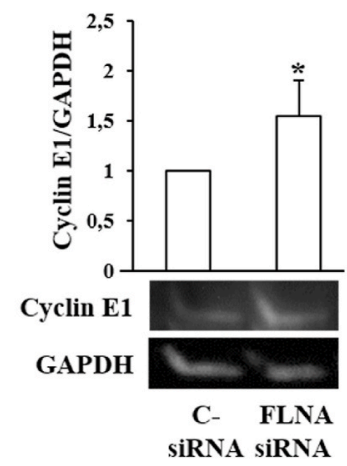

E)

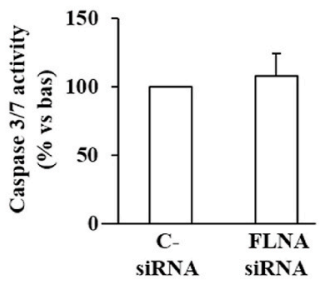

F)

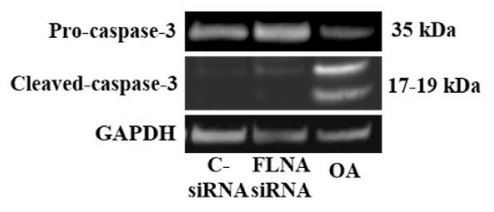

G)

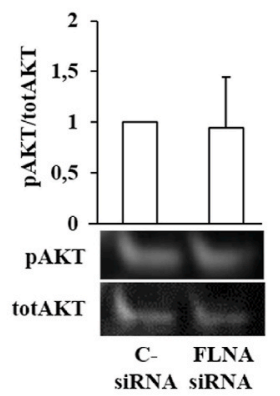

L)

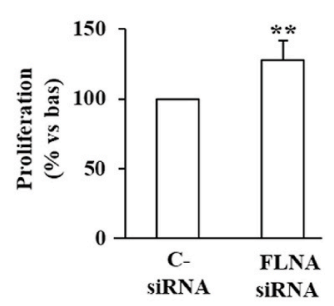

Fig. 3. FLNA knockdown potentiates IGF2 effects on cell proliferation and ERK phosphorylation. Proliferation assays in H295R (A) and SW13 (B) cells silenced for FLNA. SW13 cells were stimulated or not with IGF2 $100 \mathrm{ng} / \mathrm{ml}$ for $24 \mathrm{~h}$. BrdU was added for $2 \mathrm{~h}$ to silenced cells and its incorporation in newly synthesized DNA was measured. Experiments were repeated at least 3 times and each determination was done in triplicate. Values represent mean ( \pm S.D.) expressed as percentage of basal C- siRNA. ${ }^{*}=p<0.05$, $* *=p<0.01, * * *=p<0.001$ C) Analysis of P-ERK/total ERK ratio in H295R silenced for FLNA, IGF1R or FLNA + IGF1R. Membranes were incubated with P-ERK antibody, stripped and reprobed with total ERK antibody. Representative immunoblots and densitometric analysis of P-ERK normalized to total ERK are shown. Immunoblots of FLNA, IGF1R and GAPDH are presented to demonstrate silencing efficiency (mean $\pm \mathrm{S}$. D. from 3 independent experiments). $* *=p$ $<0.01$ vs control cells. D) Proteins were extracted from H295R silenced cells and cyclin E1 expression was evaluated. Representative immunoblots and densitometric analysis of cyclin E1 normalized to GAPDH are shown (mean \pm S.D. from 3 independent experiments). ${ }^{*}=\mathrm{p}<0.05$ vs control cells. E) FLNA knockdown does not affect cell apoptosis. Caspase-3/7 activity was measured. Data represent mean \pm S.D. of 3 independent experiments. Each determination was done in quintuplicate. F) Representative immunoblot showing pro-caspase3 , cleaved-caspase- 3 and relative GAPDH in H295R silenced for FLNA. As positive control we treated cells with okadaic acid (OA) $1 \mu \mathrm{M}$ for $24 \mathrm{~h}$. G) Proteins were extracted from H295R silenced cells. Membranes were incubated with P-AKT (Ser473) antibody, stripped and reprobed with total AKT. Representative immunoblots and densitometric analysis of P-AKT normalized to total AKT are shown. $\mathrm{H}$ ) P-ERK/total ERK ratio in ACC primary cultured cells silenced for FLNA incubated with or without IGF2 100 $\mathrm{ng} / \mathrm{ml}$ for $10 \mathrm{~min}$. The values above immunoblot images indicate densitometric analysis of P-ERK normalized to total ERK. I) Representative immunoblot and densitometric analysis of P-ERK/total ERK ratio in ACA primary cultured cells silenced for FLNA. Values represent mean ( \pm S.D.) from 4 ACAs. * $=\mathrm{p}<0.05 v s$ control cells. L) Proliferation assay in ACA primary cultured cells silenced for FLNA and stimulated with IGF2 $100 \mathrm{ng} / \mathrm{mL}$ for $24 \mathrm{~h}$. FLNA silencing induced an increase of cell proliferation compared to control cells. Values represent mean ( \pm S.D.) from 4 ACAs expressed as percentage of basal C- siRNA. ${ }^{* *}=\mathrm{p}<0.01$. 
Due to the rarity of ACC, we decided to replicate proliferation experiments in ACAs. Moreover, ACAs express higher levels of FLNA than ACCs (see paragraph 5 of Results), being more suitable for FLNA silencing experiments. In agreement with ACC cells, we found that in primary cultured ACA cells $(n=4)$ FLNA silencing increased both PERK/total ERK ratio $(2.68 \pm 1.18$-fold $v s$ control cell, $\mathrm{p}<0.05)$ (Fig. 3I and Suppl. Fig.3) and cell proliferation (127.6 $\pm 14.3 \%$ vs control cells, $\mathrm{p}<0.01$ ) (Fig. 3L).

Western blot analysis revealed that the expression of IGF2 was comparable in 2 ACAs and ACC, whereas was almost undetectable in the other 2 ACAs (Suppl. Fig. 4).

\subsection{FLNA silencing potentiates antiproliferative effects of IGF1R inhibitors Linsitinib and NVP-ADW742}

We then tested the effects of FLNA silencing on the antiproliferative effects of IGF1R inhibitors. We used Linsitinib, a dual IGF1R/IR inhibitor, and NVP-ADW742, an IGF1R-selective tyrosine kinase inhibitor [36], to discriminate the specific role of IGF1R with respect to IR.

In H295R cells silenced for FLNA the lowest concentration of Linsitinib that had a growth-inhibitory effect after $24 \mathrm{~h}$ incubation was 0.1 $\mu \mathrm{M}(-9.9 \pm 4 \%$ proliferation $v s$ basal, $\mathrm{p}<0.001)$, whereas no effect was observed in these experimental conditions in negative control cells (Fig. 4A). $1 \mu \mathrm{M}$ Linsitinib reduced cell proliferation by $38.2 \pm 16.6 \% v s$ basal ( $\mathrm{p}<0.001$ ) in FLNA silenced cells and $22.2 \pm 13.5 \%$ in negative control cells ( $\mathrm{p}<0.001 v s$ basal and $\mathrm{p}<0.05 v s$ silenced cells) (Fig. 4A).

SW13 cells were not responsive to low doses of Linsitinib (Fig. 4B). Interestingly, a significant reduction of cell proliferation was found at 5 $\mu \mathrm{M}$ Linsitinib in FLNA silenced cells $(-37.3 \pm 9.4 \% v s$ basal, $\mathrm{p}<0.05)$, but not in control cells. However, this concentration is above the human maximal plasma concentration $(3.1 \mu \mathrm{M})$ [23,37]. We cannot exclude toxic effects in cells treated with concentrations higher than $5 \mu \mathrm{M}$.

In H295R, NVP-ADW742 $0.5 \mu \mathrm{M}$ induced a decrease of cells proliferation in FLNA silenced cells $(-24.6 \pm 13.5 \%$ vs basal, $\mathrm{p}<0.05)$, and only a slight non significant effect in control cells. At $1 \mu \mathrm{M}$, it was more effective in silenced cells $(-46.3 \pm 16.1 \%$ cell proliferation, $\mathrm{p}<0.001 v \mathrm{~s}$ basal) than in control cells $(-26.5 \pm 13.8 \%, \mathrm{p}<0.001 v$ s basal and $\mathrm{p}<$ $0.05 v s$ silenced cells) (Fig. 4C). Similar to what observed with Linsitinib, SW13 were not responsive to low concentrations of NVP-ADW742, but a strong reduction of cell proliferation was observed in both control cells and silenced cells at $5 \mu \mathrm{M}$ and $10 \mu \mathrm{M}$ (Fig. 4D).

Overall, these data suggest that FLNA knockdown potentiates the effects of both IGF1R/IR and IR inhibitors on H295R cell proliferation.

The decrease in cell proliferation induced by Linsitinib and NVPADW742 was associated with a slight but not significant reduction of ERK phosphorylation (Suppl. Fig.5), with no differences between silenced and control cells.

The treatment with Linsitinib and NVP-ADW742 did not affect the expression of IGF1R, IR and FLNA (Suppl. Fig.6).

Since FLNA silencing efficiency in H295R and SW13 cells reached about $90 \%$, to test the effects of a complete absence of FLNA we used FLNA-deficient M2 and derivative rescued sub-lines A7 human melanoma cells, expressing FLNA [38]. These cells express IGF1R at similar levels in basal condition, as well as after $24 \mathrm{~h}$ IGF2 stimulation (Suppl. Fig.7A). However, we found that IGF2 was able to increase ERK phosphorylation in M2 (2.1 \pm 0.5 -fold $v s$ basal, $\mathrm{p}<0.05)$, lacking FLNA, but not in A7 cells, confirming the FLNA role in preventing IGF1R signaling (Suppl. Fig.7B). In addition, only M2 cells were responsive to Linsitinib inhibitory effects on ERK phosphorylation in the presence of IGF2 $(-81.6 \pm 32 \%$ vs IGF2 alone, $\mathrm{p}<0.01)$ (Suppl. Fig7B).

\subsection{FLNA expression in ACCs and ACAs and correlation with the IGF pathway}

We analysed FLNA expression in 10 ACC and 10 ACA tissue samples by Western blot analysis (Fig. 5A). FLNA levels were highly variable in ACC tissues, but significantly lower than in ACA (mean FLNA/GAPDH ratio $0.37 \pm 0.38$ in ACC and $0.90 \pm 0.63$ in ACA, p < 0.05) (Fig. 5B). In ACC, we observed a high heterogeneity in IGF1R expression. Mean IGF1R expression was comparable between ACCs (mean IGF1R/GAPDH ratio $0.129 \pm 0.126$ ) and ACAs (mean IGF1R/GAPDH ratio $0.190 \pm$ 0.185) (Fig. 5B). No significant correlation between IGF1R and FLNA expression has been found in ACC. Nevertheless, FLNA/IGF1R ratio and FLNA/IR ratio inversely correlated with P-ERK/total ERK ratio in ACCs (Spearman's coefficient -0.68 and -0.71 , respectively, $\mathrm{p}<0.05$ ) (Fig. 5C\&D) but not in ACAs. This suggests that low FLNA levels, in the presence of high IGF1R and/or IR amount, corresponded to an enhancement of IGF1R pathway in ACCs.
A)

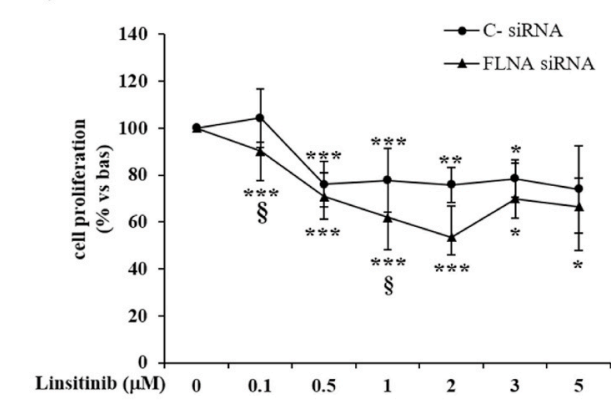

C)

C) H295R

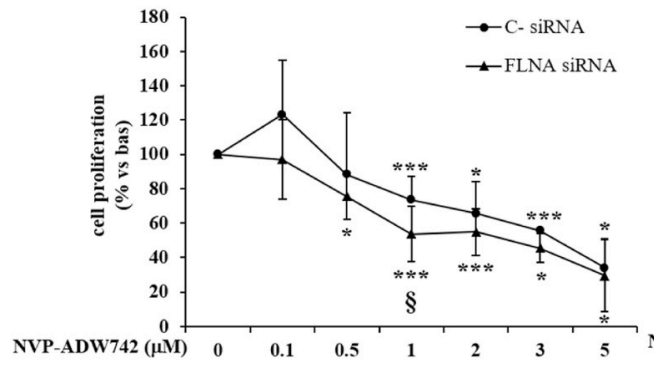

B)

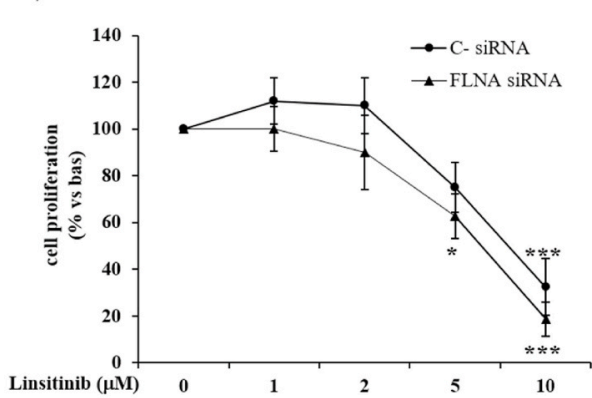

D)

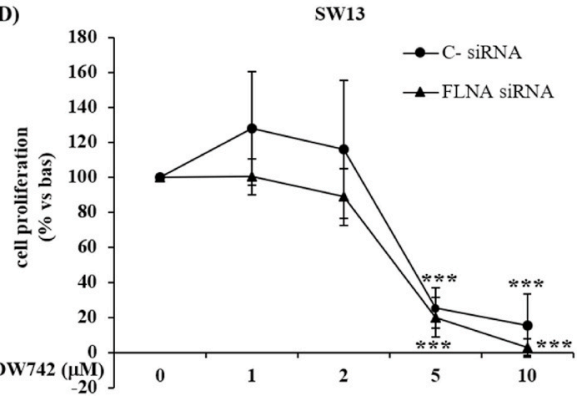

Fig. 4. FLNA silencing improves Linsitinib and NVP-ADW742 effects on cell proliferation. H295R and SW13 proliferation assays. Silenced cells were incubated for $24 \mathrm{~h}$ with or without Linsitinib (A\&B) or NVPADW742 (C\&D) at the indicated concentrations. SW13 cells were also stimulated with IGF2 $100 \mathrm{ng} / \mathrm{ml}$ for additional $24 \mathrm{~h}$. BrdU was added for $2 \mathrm{~h}$. Values represent mean ( \pm S.D.) expressed as \% respective basal. All experiments were repeated at least 3 times and each determination was done in triplicate. ${ }^{*}=\mathrm{p}<0.05,{ }^{*} * \mathrm{p}<0.01,{ }^{* * *}=\mathrm{p}<$ 0.001 vs basal condition. $\S, \mathrm{p}<0.05$ vs negative control. 
A)

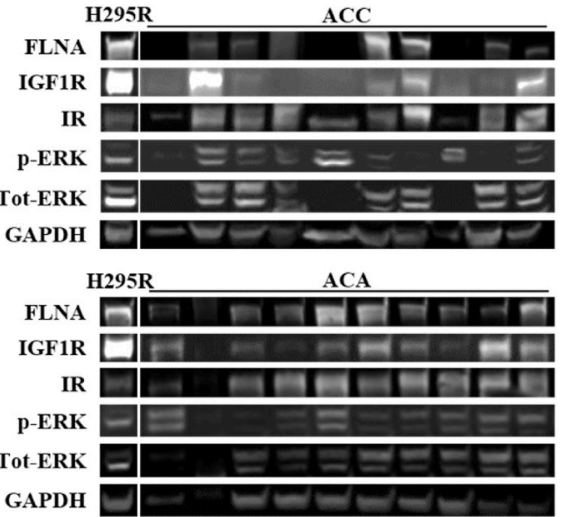

C)

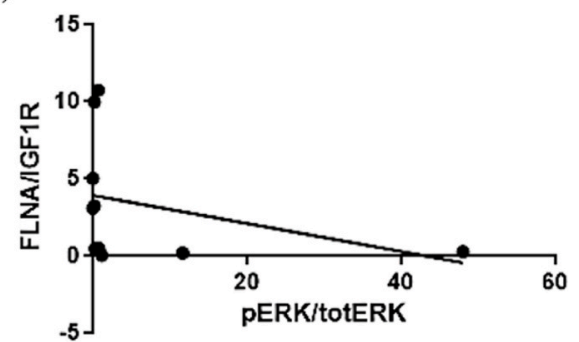

B)

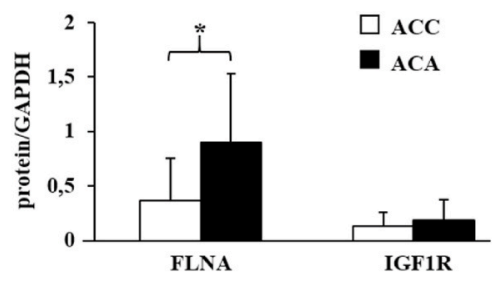

D)

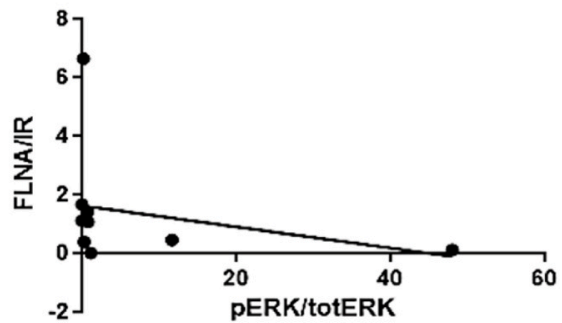

Fig. 5. FLNA expression in ACCs and in ACAs. A) Representative immunoblot of FLNA, IGF1R, IR, P-ERK, total ERK and GAPDH expression in 10 ACCs, 10 ACAs and H295R. B) The graph shows densitometric analysis of FLNA and IGF1R expression normalized to GAPDH (mean \pm S.D.). * $=\mathrm{p}$ $<$ 0.05. H295R whole cell lysates were included to normalize all the blots to the same control sample. C\&D) Scatterplot representing the inverse linear correlation between FLNA/IGF1R ratio (C) and FLNA/IR ratio (D) with pERK/total ERK ratio in ACCs.

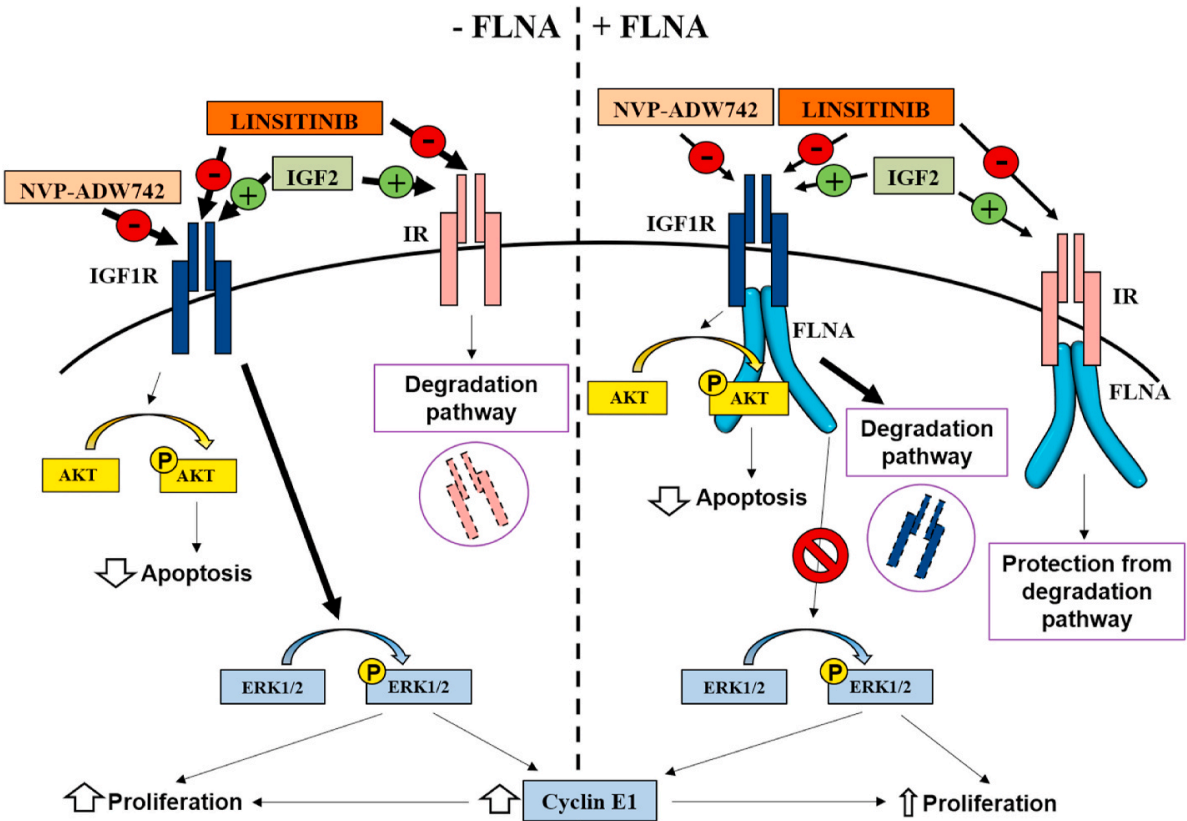

Fig. 6. Schematic representation of the FLNA impact on the signal transduction pathways in ACC cells. Left: Low/absent FLNA expression potentiates the effect of IGF2, IGF1R/IR inhibitor Linsitinib and specific IGF1R inhibitor NVP-ADW742. IGF1R mediates an increase of cell proliferation, though an efficient ERK phosphorylation and cyclin E1 expression, and a reduction of cell apoptosis through AKT phosphorylation. In the absence of FLNA, IR might be preferentially directed to a degradation pathway upon agonist stimulation. IGF1R inhibitors efficiently inhibit cell growth. Right: FLNA binds to IGF1R and IR, with opposite effects. FLNA might promote IGF1R downregulation, while protecting IR from degradation upon IGF2 binding. Furthermore, FLNA functions as a specific repressor of the IGF2-induced signaling cascade that, through ERK phosphorylation and cyclin E1 expression, increases cell growth, whereas the AKT pathway is not affected by FLNA. In the presence of FLNA, Linsitinib and NVP-ADW742 display a minor impact on cell proliferation.

\section{Discussion}

The present study identified cytoskeleton protein FLNA as a repressor of IGF2 signalling and investigated how loss of FLNA affects IGF1R signalling and the response to anti-IGF1R therapies.

The activation of the complex IGF axis, triggered by IGF2 overexpression in ACC, promotes the autonomous growth of ACC cells. IGF2 binds to IGF1R leading to activation of MAPKs and PI3K/AKT pathways, that increased cancer cell proliferation, survival and migration.

Moreover, IGF2 binds to the isoform A of the insulin receptor (IRA), whose contribution to IGF2 mitogenic effects has been poorly clarified, and to the mannose 6-phosphate/insulin-like growth factor 2 receptor (IGF2R), a scavenger receptor involved in the internalization and degradation of IGF2. Recently, an high expression of IGF2R has been observed in most ACCs, suggesting that a high level of IGF2R protein might counteract the growth-stimulating effects of IGF2 in adrenocortical tumorigenesis [20]. Despite promising results of preclinical studies [15,16], IGF1R/IR inhibitors failed in clinical trials in most ACC patients. To date, molecular determinants of responsiveness are unknown.

The ACC cell line H295R is a good model to study the regulation of IGF system in the development of these tumors, since it presents a high abundance of IGF2 mRNA and protein $[16,34,35]$. The use of SW13 cells 
is more controversial. They are commonly used as a model for non-functional adrenocortical cancer, but it is unclear whether they derive from a primary cancer arising from the adrenal cortex or from metastasis to the adrenal cortex [39]. However, we decided to use this cell line, endogenously expressing IGF1R, but not IGF2, to test the effects of the absence of IGF2. Moreover, we used primary ACC cell cultures derived from human surgically removed ACCs and ACAs to assess FLNA effects in a more representative model.

First, we demonstrated that FLNA interacts with both IGF1R and IR in H295R and SW13 cells by in situ proximity ligation assay, a method that allows to detect the close proximity of two proteins in intact fixed cells.

IGF2 stimulation induced opposite effects on FLNA binding for IGF1R and IR, increasing IGF1R-FLNA interaction, while reducing IRFLNA binding. Subsequent experiments testing IGF1R and IR expression revealed that the presence of FLNA is able to differentially regulate receptors expression upon IGF2 stimulation. In the presence of IGF2, that is produced and secreted in culture medium by H295R and primary cells, and exogenously added to SW13 cells, genetic silencing of FLNA induced an increase of IGF1R expression levels in both ACC cell lines and primary cultured cells. In contrast, IR was reduced (in cell lines) or unchanged (in primary cells) after FLNA silencing. Nevertheless, FLNA transfection did not impact on IGF1R and IR expression, a result in line with previous observation on scaffold proteins, whose overexpression might induce a dilution of the partner molecules [40].

Further experiments are required to investigate the molecular mechanisms underlying the FLNA effects on the expression of IGF1R and IR. Based on previously published data, we can hypothesize that FLNA might promote IGF1R downregulation, while protecting IR from degradation upon IGF2 binding (Fig. 6). Indeed, it is well recognized that FLNA is directly involved in regulating endocytosis processes, postendocytic trafficking and downregulation of different membrane receptors [30,41-45]. In particular, the epidermal growth factor receptor (EGFR) requires FLNA for sorting into the degradation pathway in melanoma cells [43]. The authors demonstrated that EGFR showed comparable rates of EGF-mediated endocytosis in M2 (lacking FLNA) and A7 (expressing FLNA) cells, but in M2 cells it exhibited marked resistance to degradation, compared to A7 cells. Accordingly, internalized EGFR colocalized with the lysosomal marker LAMP-1 in A7 cells but not M2 cells [43]. We can hypothesize that in ACC cells, upon IGF2 binding, IGF1R recruits FLNA, that orchestrates IGF1R internalization and subsequent degradative process (Fig. 6). The hypothesis of an agonist-dependent mechanism is supported by the observation that FLNA silencing induced an effect on IGF1R expression levels only in the presence of IGF2 stimulation, but not in basal condition.

It is worth noting that the IR antibody recognizes both IRA and IRB, since no antibody able to discriminate between the two isoforms of IR is currently available. Both these isoforms are expressed in ACC [20]. While IRA stimulates cancer cell proliferation and survival, IRB is more closely linked to metabolic regulation [46]. Since IRA, but not IRB, is a high-affinity receptor for IGF2 [47], we can hypothesize that the observed IGF2-induced alterations of IR are imputable to IRA.

We then assessed the impact of the FLNA-induced changes in receptors expression on downstream intracellular events induced by IGF2. In both cell lines and primary cultured ACC cells, we found an enhancement of IGF2 effects on cell proliferation and ERK phosphorylation after FLNA depletion by siRNA approaches. On the contrary, FLNA knockdown did not affect AKT phosphorylation and apoptosis induction. This selective enhancement of a specific pathway indicates that the observed effects are not simply the result of an increased IGF1R expression but are also due to the absence of a negative regulatory activity of FLNA on MAPK cascade (Fig. 6). A similar inhibitory effect of FLNA was observed in colon carcinoma cells, in which FLNA silencing induced an activation of EGFR, AKT and ERK [48], whereas FLNA knockdown in mouse lung exerted an opposite effect, impairing AKT and ERK activation [49], supporting the specificity of the observed mechanism for ACC compared to other tumors. In this regard, it was previously demonstrated that FLNA may play a dual role in cancer, also depending on its intracellular localization [50].

Overall, these results suggest that FLNA in ACC is a specific repressor of the IGF2-induced signaling cascade that, through ERK activation, promotes cell proliferation. In the absence of FLNA, the increased expression of IGF1R associated with the loss of the FLNA regulatory activity on ERK pathway, concur to promote IGF2 induced cell growth.

Since in the absence of FLNA the expression of IR is very low, the contribution of IR to the observed cell growth can be considered negligible.

In agreement, a previous study showed that loss of Flna in mouse neural progenitor cells resulted in enhanced IGF1R signalling [29]. Moreover, a similar FLNA role in impairing the IR ability to activate ERK, but not AKT, was demonstrated in melanoma cell line A7 compared to M2 [28]. The authors showed that M2 cells exhibited normal IR signalling, whereas FLNA-expressing A7 cells were unable to elicit insulin-dependent She tyrosine phosphorylation and ERK activation, with no alterations in IR-stimulated phosphorylation of insulin receptor substrate-1 or activation of the phosphatidylinositol 3-kinase/AKT cascade [28]. Interestingly, in the presence of FLNA, insulin-dependent translocation of Shc, SOS1, and ERK to lipid raft was reduced. Moreover, the overexpression of a C-terminal fragment of FLNA in HepG2 hepatoma cells blocked IR-FLNA interaction and potentiated the activity of ERK, but not AKT, suggesting that FLNA interacts with IR to exert an inhibitory tone along the MAPK activation pathway [28]. Although further experiments are required to investigate the mechanism involved in ERK pathway regulation by FLNA in ACC cells, we can hypothesized a similar mechanisms, in which FLNA impaired translocation of components of ERK pathway to the membrane rafts following IGF2 stimulation. Another hypothesis could be a contribution of FLNA in promoting selective $\beta$-arrestins recruitment to IGF1R upon IGF2 stimulation, since FLNA is a known $\beta$-arrestin2 binding partner and $\beta$-arrestins 1 and 2 are differentially involved in IGF1R desensitization, trafficking and signaling [51].

Since FLNA turns down IGF2/IGF1R axis activation, we decided to test a possible role of FLNA in determining ACC cells responses to IGF1R inhibitors.

Our results showed that the loss of FLNA in H295R increased cell responsiveness to dual IGF1R-IR inhibitor Linsitinb and to the specific IGF1R inhibitor NVP-ADW742. In particular, FLNA silencing made cells responsive to lower inhibitors concentrations, and at a concentration of $1 \mu \mathrm{M}$ the inhibition was significantly greater in silenced than in control cells.

SW13 cells were unresponsive to both inhibitors within the range of human maximal plasma concentrations (from 1.7 to $3.1 \mu \mathrm{M}$ ) [23,37], however at $5 \mu \mathrm{M}$, Linsitinib exerted a significant antiproliferative effect only in the absence of FLNA.

Our data demonstrated that Linsitinib and NVP-ADW742 exerted similar effects, supporting a major role for IGF1R. This result is in agreement with the FLNA silencing experiments which suggest that the contribution of IR to the cell growth can be considered negligible.

The cell model commonly used to study FLNA functions is the FLNAdeficient melanoma cell line M2, together with the FLNA-reconstituted cell line A7 [38]. These cell lines expressed IGF1R at comparable levels in basal and IGF2 stimulated conditions, suggesting that the effects of FLNA on the regulation of the agonist-stimulated IGF1R expression is specific of ACC cells. Nevertheless, IGF2 was able to induce ERK phosphorylation in M2 but not in A7 cells, in agreement with the FLNA role as suppressor of IGF1R signaling. In addition, A7 cells were completely resistant to inhibitory effects of Linsitinib, whereas it strongly reduced ERK activation in M2 cells, in line with what observed in ACC cell lines depleted of FLNA.

In human surgically removed ACC tissue samples, FLNA was expressed at variable levels, but mean FLNA expression in ACC was significantly lower than in ACA tissues, supporting an increased 
activation of IGF2 axis in ACC, based on our in vitro results. We found a comparable expression of IGF1R in ACC and ACA, as previously shown [15], although highly variable in ACC samples. No significant correlation was found between FLNA and IGF1R expression in ACC tissue samples, however FLNA/IGF1R ratio was inversely correlated with phosphorylated-ERK/total ERK ratio in ACCs, but not in ACAs. This suggests that low FLNA levels in ACCs, in the presence of high IGF1R expression, enhance IGF2 signal toward ERK. Due to the small size of ACC group, no correlation between their clinico-pathological features and the expression of FLNA have been made. Admittedly, further studies in a large cohort of patients are required to confirm the expression data and functional studies, and to evaluate the use of FLNA as a new ACC prognostic factor. Due to the small number of primary cultures and tissue samples analysed, our conclusions might be applicable only in some subgroups of patients.

Overall, these data support a FLNA role in decreasing both IGF2 mitogenic effects and the efficacy of IGF1R inhibitors. We can hypothesize that in the absence of FLNA, IGF2/IGF1R pathway represents the main trigger for tumor cell growth, and in this condition the inhibition of IGF1R can reach a major impact on cell proliferation. The loss of FLNA might thus represent a novel predictive biomarker for the identification of subpopulation of patients in which IGF1R-targeted therapy can be effective.

\section{CRediT authorship contribution statement}

R. Catalano: Conceptualization, Methodology, Investigation, Writing - original draft. E. Giardino: Investigation. D. Treppiedi: Investigation. F. Mangili: Investigation. V. Morelli: Resources. F.M. Elli: Investigation. A.L. Serban: Formal analysis. M. Luconi: Resources. M. Mannelli: Resources. A. Spada: Supervision. M. Arosio: Supervision. G. Mantovani: Writing - review \& editing, Supervision, Project administration, Funding acquisition. E. Peverelli: Conceptualization, Validation, Writing - review \& editing, Supervision, Project administration, Funding acquisition.

\section{Acknowledgements}

This work was supported by AIRC (Associazione Italiana Ricerca Cancro) grant to G.M. (IG 2017-20594), Italian Ministry of Health grant to G.M. (PE-2016-02361797), Ricerca Corrente Funds from the Italian Ministry of Health and Progetti di Ricerca di Interesse Nazionale (PRIN) grant to E.P. (2017N8CK4K).

\section{Appendix A. Supplementary data}

Supplementary data related to this article can be found at https ://doi.org/10.1016/j.canlet.2020.10.022.

\section{Declarations of interest}

None.

\section{Declaration of interests}

The authors declare that they have no known competing financial interests or personal relationships that could have appeared to influence the work reported in this paper.

\section{References}

[1] T.M. Kerkhofs, R.H. Verhoeven, J.M. Van der Zwan, J. Dieleman, M.N. Kerstens, T. P. Links, et al., Adrenocortical carcinoma: a population-based study on incidence and survival in The Netherlands since 1993, Eur. J. Canc. 49 (2013) 2579-2586, https://doi.org/10.1016/j.ejca.2013.02.034.
[2] T. Else, A.C. Kim, A. Sabolch, V.M. Raymond, A. Kandathil, E.M. Caoili, et al., Adrenocortical carcinoma, Endocr. Rev. 35 (2014) 282-326, https://doi.org/ 10.1210/er.2013-1029.

[3] M. Fassnacht, O.M. Dekkers, T. Else, E. Baudin, A. Berruti, R. de Krijger, et al., European society of endocrinology clinical practice guidelines on the management of adrenocortical carcinoma in adults, in collaboration with the European network for the study of adrenal tumors, Eur. J. Endocrinol. 179 (2018) G1-G46, https:// doi.org/10.1530/EJE-18-0608.

[4] M. Fassnacht, B. Allolio, Clinical management of adrenocortical carcinoma, Best Pract. Res. Clin. Endocrinol. Metabol. 23 (2009) 273-289, https://doi.org/ 10.1016/j.beem.2008.10.008.

[5] J. Crona, F. Beuschlein, Adrenocortical carcinoma - towards genomics guided clinical care, Nat. Rev. Endocrinol. 15 (2019) 548-560, https://doi.org/10.1038/ s41574-019-0221-7.

[6] T. Vanbrabant, M. Fassnacht, G. Assie, O.M. Dekkers, Influence of hormonal functional status on survival in adrenocortical carcinoma: systematic review and meta-analysis, Eur. J. Endocrinol. 179 (2018) 429-436, https://doi.org/10.1530/ EJE-18-0450.

[7] S. Zheng, A.D. Cherniack, N. Dewal, R.A. Moffitt, L. Danilova, B.A. Murray, et al., Comprehensive pan-genomic characterization of adrenocortical carcinoma, Canc. Cell 29 (2016) 723-736, https://doi.org/10.1016/j.ccell.2016.04.002.

[8] G. Assié, A. Jouinot, M. Fassnacht, R. Libé, S. Garinet, L. Jacob, et al., Value of molecular classification for prognostic assessment of adrenocortical carcinoma, JAMA Oncol 5 (2019), https://doi.org/10.1001/jamaoncol.2019.1558.

[9] C. Gicquel, X. Bertagna, H. Schneid, M. Francillard-Leblond, J.P. Luton, F. Girard, et al., Rearrangements at the $11 \mathrm{p} 15$ locus and overexpression of insulin-like growth factor-II gene in sporadic adrenocortical tumors, J. Clin. Endocrinol. Metab. 78 (1994) 1444-1453, https://doi.org/10.1210/jcem.78.6.7911125.

[10] C. Gicquel, M.L. Raffin-Sanson, V. Gaston, X. Bertagna, P.F. Plouin, M. Schlumberger, et al., Structural and functional abnormalities at 11p15 are associated with the malignant phenotype in sporadic adrenocortical tumors: study on a series of 82 tumors, J. Clin. Endocrinol. Metab. 82 (1997) 2559-2565, https:// doi.org/10.1210/jcem.82.8.4170.

[11] N. Boulle, A. Logié, C. Gicquel, L. Perin, Y. Le Bouc, Increased levels of insulin-like growth factor II (IGF-II) and IGF-binding protein-2 are associated with malignancy in sporadic adrenocortical tumors, J. Clin. Endocrinol. Metab. 83 (1998) 1713-1720, https://doi.org/10.1210/jcem.83.5.4816.

[12] T.J. Giordano, D.G. Thomas, R. Kuick, M. Lizyness, D.E. Misek, A.L. Smith, et al., Distinct transcriptional profiles of adrenocortical tumors uncovered by DNA microarray analysis, Am. J. Pathol. 162 (2003) 521-531, https://doi.org/10.1016/ S0002-9440(10)63846-1.

[13] A. Schmitt, P. Saremaslani, S. Schmid, V. Rousson, M. Montani, D.M. Schmid, et al., IGFII and MIB1 immunohistochemistry is helpful for the differentiation of benign from malignant adrenocortical tumours, Histopathology 49 (2006) 298-307, https://doi.org/10.1111/j.1365-2559.2006.02505.x.

[14] F. de Fraipont, M. El Atifi, N. Cherradi, G. Le Moigne, G. Defaye, R. Houlgatte, et al., Gene expression profiling of human adrenocortical tumors using complementary deoxyribonucleic Acid microarrays identifies several candidate genes as markers of malignancy, J. Clin. Endocrinol. Metab. 90 (2005) 1819-1829, https://doi.org/10.1210/jc.2004-1075.

[15] M.Q. Almeida, M.C. Fragoso, C.F. Lotfi, M.G. Santos, M.Y. Nishi, M.H. Costa, et al., Expression of insulin-like growth factor-II and its receptor in pediatric and adult adrenocortical tumors, J. Clin. Endocrinol. Metab. 93 (2008) 3524-3531, https:// doi.org/10.1210/jc.2008-0065.

[16] F.M. Barlaskar, A.C. Spalding, J.H. Heaton, R. Kuick, A.C. Kim, D.G. Thomas, et al., Preclinical targeting of the type I insulin-like growth factor receptor in adrenocortical carcinoma, J. Clin. Endocrinol. Metab. 94 (2009) 204-212, https:// doi.org/10.1210/jc.2008-1456.

[17] H.M. Nielsen, A. How-Kit, C. Guerin, F. Castinetti, H.K. Vollan, C. De Micco, et al., Copy number variations alter methylation and parallel IGF2 overexpression in adrenal tumors, Endocr. Relat. Canc. 22 (2015) 953-967, https://doi.org/ 10.1530/ERC-15-0086.

[18] C. Drelon, A. Berthon, B. Ragazzon, F. Tissier, R. Bandiera, I. Sahut-Barnola, et al., Analysis of the role of Igf2 in adrenal tumour development in transgenic mouse models, PloS One 7 (2012), e44171, https://doi.org/10.1371/journal. pone.0044171.

[19] M. Guillaud-Bataille, B. Ragazzon, A. de Reyniès, C. Chevalier, I. Francillard, O. Barreau, et al., IGF2 promotes growth of adrenocortical carcinoma cells, but its overexpression does not modify phenotypic and molecular features of adrenocortical carcinoma, PloS One 9 (2014), e103744, https://doi.org/10.1371/ journal.pone.0103744.

[20] M.C. De Martino, P.M. van Koetsveld, R.A. Feelders, W.W. de Herder, F. Dogan, J. A.M.J.L. Janssen, et al., IGF and mTOR pathway expression and in vitro effects of linsitinib and mTOR inhibitors in adrenocortical cancer, Endocrine 64 (2019) 673-684, https://doi.org/10.1007/s12020-019-01869-1.

[21] T. Kamio, K. Shigematsu, K. Kawai, H. Tsuchiyama, Immunoreactivity and receptor expression of insulin like growth factor I and insulin in human adrenal tumors. An immunohistochemical study of 94 cases, Am. J. Pathol. 138 (1991) 83-91. PMID; 1702931 PMCID: PMC1886050.

[22] L. Girnita, C. Worrall, S.I. Takahashi, S. Seregard, A. Girnita, Something old, something new and something borrowed: emerging paradigm of insulin-like growth factor type 1 receptor (IGF-1R) signalling regulation, Cell. Mol. Life Sci. 71 (2014) 2403-2427, https://doi.org/10.1007/s00018-013-1514-y.

[23] M. Fassnacht, A. Berruti, E. Baudin, M.J. Demeure, J. Gilbert, H. Haak, et al., Linsitinib (OSI-906) versus placebo for patients with locally advanced or metastatic 
adrenocortical carcinoma: a double-blind, randomised, phase 3 study, Lancet Oncol. 16 (2015) 426-435, https://doi.org/10.1016/S1470-2045(15)70081-1.

[24] G. Mantovani, D. Treppiedi, E. Giardino, R. Catalano, F. Mangili, P. Vercesi, et al., Cytoskeleton actin-binding proteins in clinical behavior of pituitary tumors, Endocr. Relat. Canc. 26 (2019) R95-R108, https://doi.org/10.1530/ERC-18-0442.

[25] E. Vitali, V. Cambiaghi, A. Zerbi, C. Carnaghi, P. Colombo, E. Peverelli, et al., Filamin-A is required to mediate SST2 effects in pancreatic neuroendocrine tumours, Endocr. Relat. Canc. 23 (2016) 181-190, https://doi.org/10.1530/ERC$15-0358$.

[26] Q.Q. Shao, T.P. Zhang, W.J. Zhao, Z.W. Liu, L. You, L. Zhou, et al., Filamin A: insights into its exact role in cancers, Pathol. Oncol. Res. 22 (2016) 245-252, https://doi.org/10.1007/s12253-015-9980-1.

[27] F. Nakamura, T.P. Stossel, J.H. Hartwig, The filamins: organizers of cell structure and function, Cell Adhes. Migrat. 5 (2011) 160-169, https://doi.org/10.4161/ cam.5.2.14401.

[28] H.J. He, S. Kole, Y.K. Kwon, M.T. Crow, M. Bernier, Interaction of filamin A with the insulin receptor alters insulin-dependent activation of the mitogen-activated protein kinase pathway, J. Biol. Chem. 278 (2003) 27096-27104, https://doi.org/ 10.1074/jbc.M301003200.

[29] S.L. Houlihan, A.A. Lanctot, Y. Guo, Y. Feng, Upregulation of neurovascular communication through filamin abrogation promotes ectopic periventricular neurogenesis, Elife 5 (2016) 17823, https://doi.org/10.7554/eLife.17823.

[30] E. Peverelli, E. Giardino, D. Treppiedi, E. Vitali, V. Cambiaghi, M. Locatelli, et al., Filamin A (FLNA) plays an essential role in somatostatin receptor 2 (SST2) signaling and stabilization after agonist stimulation in human and rat somatotroph tumor cells, Endocrinology 155 (2014) 2932-2941, https://doi.org/10.1210/ en.2014-1063.

[31] G. Pearson, B. Chai, T. Vozheiko, X. Liu, M. Kandarpa, R.C. Piper, et al., Clec16a, Nrdp1, and USP8 form a ubiquitin-dependent tripartite complex that regulates $\beta$-cell mitophagy, Diabetes 67 (2018) 265-277, https://doi.org/10.2337/db170321.

[32] E. Peverelli, L. Olgiati, M. Locatelli, P. Magni, M.F. Fustini, G. Frank, et al., The dopamine-somatostatin chimeric compound BIM-23A760 exerts antiproliferative and cytotoxic effects in human non-functioning pituitary tumors by activating ERK1/2 and p38 pathways, Canc. Lett. 288 (2010) 170-176, https://doi.org/ 10.1016/j.canlet.2009.06.034.

[33] M.C. De Martino, P.M. van Koetsveld, R.A. Feelders, D. Sprij-Mooij, M. Waaijers, S W. Lamberts, et al., The role of mTOR inhibitors in the inhibition of growth and cortisol secretion in human adrenocortical carcinoma cells, Endocr. Relat. Canc. 19 (2012) 351-364, https://doi.org/10.1530/ERC-11-0270.

[34] E. Buck, P.C. Gokhale, S. Koujak, E. Brown, A. Eyzaguirre, N. Tao, et al., Compensatory insulin receptor (IR) activation on inhibition of insulin-like growth factor-1 receptor (IGF-1R): rationale for cotargeting IGF-1R and IR in cancer, Mol. Canc. Therapeut. 9 (2010) 2652-2664, https://doi.org/10.1158/1535-7163.MCT10-0318.

[35] A. Logié, N. Boulle, V. Gaston, L. Perin, P. Boudou, Y. Le Bouc, et al., Autocrine role of IGF-II in proliferation of human adrenocortical carcinoma NCI H295R cell line, J. Mol. Endocrinol. 23 (1999) 23-32, https://doi.org/10.1677/jme.0.0230023.

[36] C.S. Mitsiades, N.S. Mitsiades, C.J. McMullan, V. Poulaki, R. Shringarpure, M. Akiyama, et al., Inhibition of the insulin-like growth factor receptor-1 tyrosine kinase activity as a therapeutic strategy for multiple myeloma, other hematologic malignancies, and solid tumors, Canc. Cell 5 (2004) 221-230, https://doi.org/ 10.1016/s1535-6108(04)00050-9.
[37] I. Puzanov, C.R. Lindsay, L. Goff, J. Sosman, J. Gilbert, J. Berlin, et al., A phase I study of continuous oral dosing of OSI-906, a dual inhibitor of insulin-like growth factor-1 and insulin receptors, in patients with advanced solid tumors, Clin. Canc. Res. 21 (2015) 701-711, https://doi.org/10.1158/1078-0432.CCR-14-0303.

[38] C.C. Cunningham, J.B. Gorlin, D.J. Kwiatkowski, J.H. Hartwig, P.A. Janmey, H. R. Byers, et al., Actin-binding protein requirement for cortical stability and efficient locomotion, Science 255 (1992) 325-327, https://doi.org/10.1126/ science. 1549777.

[39] T. Wang, W.E. Rainey, Human adrenocortical carcinoma cell lines, Mol. Cell. Endocrinol. 351 (2012) 58-65, https://doi.org/10.1016/j.mce.2011.08.041.

[40] W.R. Burack, A.S. Shaw, Signal transduction: hanging on a scaffold, Curr. Opin. Cell Biol. 12 (2000) 211-216, https://doi.org/10.1016/s0955-0674(99)00078-2.

[41] D. Treppiedi, F. Mangili, E. Giardino, R. Catalano, M. Locatelli, A. Lania, et al., Cytoskeleton protein Filamin A is required for efficient Somatostatin receptor type 2 internalization and recycling through Rab 5 and Rab 4 sorting endosomes in tumor somatotroph cells, Neuroendocrinology (2019), https://doi.org/10.1159/ 000503791.

[42] M. Pons, I. Izquierdo, M. Andreu-Carbó, G. Garrido, J. Planagumà, O. Muriel, et al., Phosphorylation of filamin A regulates chemokine receptor CCR2 recycling, J. Cell Sci. 130 (2017) 490-501, https://doi.org/10.1242/jcs.193821.

[43] J.L. Fiori, T.N. Zhu, M.P. O'Connell, K.S. Hoek, F.E. Indig, B.P. Frank, et al., Filamin A modulates kinase activation and intracellular trafficking of epidermal growth factor receptors in human melanoma cells, Endocrinology 150 (2009) 2551-2560, https://doi.org/10.1210/en.2008-1344.

[44] E. Peverelli, G. Mantovani, E. Vitali, F.M. Elli, L. Olgiati, S. Ferrero, et al., FilaminA is essential for dopamine $\mathrm{d} 2$ receptor expression and signaling in tumorous lactotrophs, J. Clin. Endocrinol. Metab. 97 (2012) 967-977, https://doi.org/ 10.1210/jc.2011-2902.

[45] F. Nakamura, T.P. Stossel, J.H. Hartwig, The filamins: organizers of cell structure and function, Cell Adhes. Migrat. 5 (2011) 160-169, https://doi.org/10.4161/ cam.5.2.14401.

[46] A. Belfiore, F. Frasca, G. Pandini, L. Sciacca, R. Vigneri, Insulin receptor isoforms and insulin receptor/insulin-like growth factor receptor hybrids in physiology and disease, Endocr. Rev. 30 (2009) 586-623, https://doi.org/10.1210/er.2008-0047.

[47] F. Frasca, G. Pandini, P. Scalia, L. Sciacca, R. Mineo, A. Costantino, et al., Insulin receptor isoform A, a newly recognized, high-affinity insulin-like growth factor II receptor in fetal and cancer cells, Mol. Cell Biol. 19 (1999) 3278-3288, https://doi. org/10.1128/mcb.19.5.3278.

[48] K. Wang, T.N. Zhu, R.J. Zhao, Filamin A regulates EGFR/ERK/Akt signaling and affects colorectal cancer cell growth and migration, Mol. Med. Rep. 20 (2019) 3671-3678, https://doi.org/10.3892/mmr.2019.10622.

[49] R.K. Nallapalli, M.X. Ibrahim, A.X. Zhou, S. Bandaru, S. Naresh, B. Redfors, et al., Targeting filamin A reduces K-RAS-induced lung adenocarcinomas and endothelial response to tumor growth in mice, Mol. Canc. 11 (2012) 50, https://doi.org/ 10.1186/1476-4598-11-50.

[50] R.M. Savoy, P.M. Ghosh, The dual role of filamin A in cancer: can't live with (too much of) it, can't live without it, Endocr. Relat. Canc. 20 (6) (2013) R341-R356, https://doi.org/10.1530/ERC-13-0364.

[51] N. Suleymanova, C. Crudden, T. Shibano, C. Worrall, I. Oprea, A. Tica, et al., Functional antagonism of $\beta$-arrestin isoforms balance IGF-1R expression and signalling with distinct cancer-related biological outcomes, Oncogene 36 (2017) 5734-5744, https://doi.org/10.1038/onc.2017.179. 